SPECTRA OF SCATTERED RADIATION AT POINTS OFF THE BEAM AXIS

\author{
$\mathbf{A}$ \\ THESIS \\ Submitted to \\ THE FACULTY OF GRADUATE STUDIES \\ in Partial Fulfilment of \\ the Requirements for \\ THE DEGREE OF MASTER OF SCIENCE \\ In \\ THE DEPARTMENT OF PHYSICS \\ UNIVERSITY OF SASKATCHEWAN
}

by

STANLEY MAK

Written under the Supervision of Dr. D.V. CORMACK

Saskatoon, Saskatchewan

July, 1959.

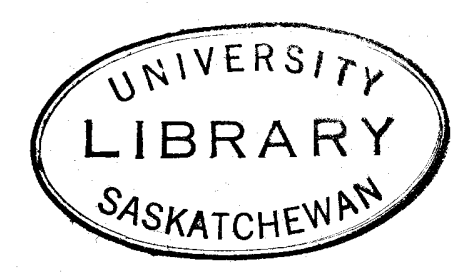

The University of Saskatchewan claims copyright in conjunction with the author. Use shall not be made of the material contained herein without proper acknowledgrent. 
ACKNOWTLEDGMENTS

The author wishes to express his thanks to Dr. D.V. Cormack for his advice and assistance throughout this investigation. Thanks are also to Mr. Charles Kresse for his assistance in instrumentation and Miss Sylvia Fedoruk for the loan of electronic equipnent. The author also acknowledges gratefully the financial assistance given by the National Research Council in the form of a bursary. The National Cancer Institute of Canada and Saskatchewan Division of the Canadian Cancer Society also assisted this project financially. The use of the facllities of the Saskatoon Cancer Glinic is gratefully acknowledged. 


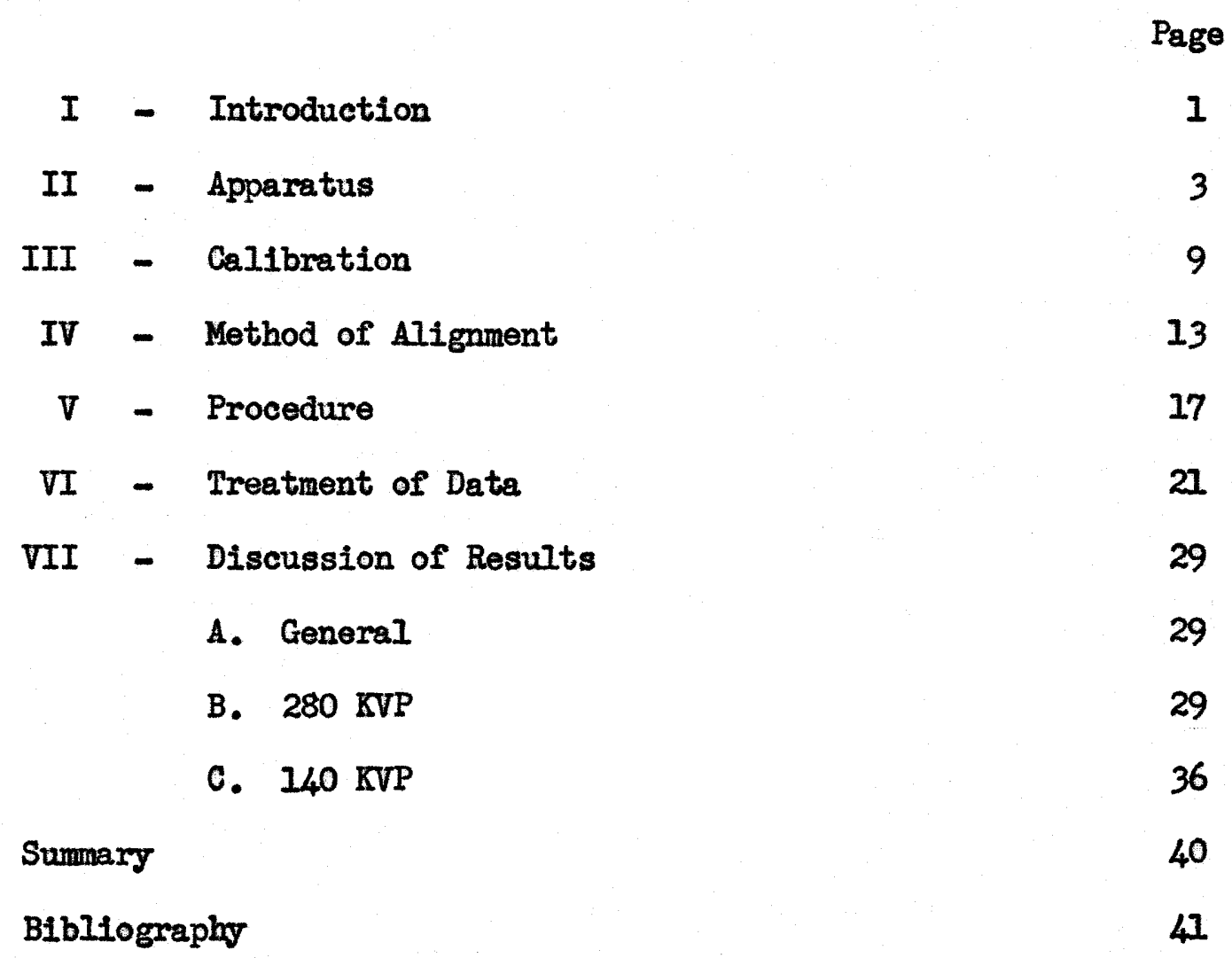


Page

Figure I Schematic Diagram of Apparatus

Figure II Orientation for $\varphi=0^{\circ} \quad 6$

Figure III Block Diagram of Analyzing System with Circuit Diagram of Cathode Follower

Figure IV Arrangement for Obtaining

$\mathrm{K}$-Characteristic X-rays

Figure VI Arrangement for Alignment of Apparatus 14

Figure VIIa Differential Scattered Spectra - 280 KVP 19

Figure VIIb Differential Scattered Spectra - 140 KVP 20

Figure VIII Integration of Scattered Spectra with

Respect to $\varphi$

Figure IX Integration of Scattered Spectra with Respect to $\theta \quad 26$

Figure $\quad$ Xa Integrated Scattered Spectra - 280 KVP 27

Figure $\quad X b \quad$ Integrated Scattered Spectra - 140 KVP 28

Figure XI Comparison with Bruce's Data -

Scattered Spectra - 280 KVP 


\section{LIST OF FIGURES}

(Cont'd)

\section{Page}

Figure XII Separation of Once-Scattered Photons from Multiply-Scattered Photons $280 \mathrm{KVP}$, at Centre

Figure XIIb Separation of Once-Scattered Photons from Maltiply-Scattered Photons $280 \mathrm{KVP}, 1.47 \mathrm{~cm}$ Inside

Figure XIII Focal Skin Distance Extrapolation 


\section{LIST OF TABLES}

Page

TABLE I Materials used for Calibration

10

TABLE II Correction Factors for Non-Linearity

of Calibration Curve 21

TABLE III Scattered Spectra 25

TABLE IV Scattered Dose : $280 \mathrm{KVP} \quad 31$

TABIE V Scattered Dose : $140 \mathrm{KVP}$ 


\section{ABSTRACT}

In radiological physics, a knowledge of the spectral distribution of radiation reaching a point is very important. Although the dose gives the amount of radiation at the point, it is the spectral distribution which determines the effects, for instance, the energy absorbed by the irradiated medium.

In an irradiated medium radiation reaching a point consists of primary and scattered radiation. The scattered radiation becomes more important as the depth is increased.

In this investigation, the spectral distributions of scattered radiation at $1.47 \mathrm{~cm}$ inside, at $1.88 \mathrm{~cm}$ outside the boundary of the field and at the central axis were measured with a scintillation spectrometer for two qualities of X-rays, $280 \mathrm{KVP}$, HVL of $2.5 \mathrm{~mm} \mathrm{Cu}$ and $140 \mathrm{KVP}$, HVL of $1.45 \mathrm{~mm}$ Al. A circular beam of $100 \mathrm{~cm}^{2}$ at FSD of $60 \mathrm{~cm}$ was used. Measurements were carried out at $5 \mathrm{~cm}$ depth for $280 \mathrm{KVP}$ and $2 \mathrm{~cm}$ depth for $140 \mathrm{KVP}$.

It was found that for 280 KVP radiation, the shapes of the integrated spectre inside the field, outside the field and at the centre are nearly the same. However, the dose received at $1.47 \mathrm{~cm}$ inside is $73 \%$ of that at the centre and $1.88 \mathrm{~cm}$ outside is $37 \%$ of that at the centre. It should be pointed out that at the centre, the scattered radiation contributes about half the total dose.

For $140 \mathrm{KVP}$ radiation, the peak of the scattered spectrun becomes broader as the distance from the centre is increased. The dose received 
at $1.47 \mathrm{~cm}$ inside is $83 \%$ of that at the centre and $1.88 \mathrm{~cm}$ outside is $25 \%$ of that at the centre. For the central point the scattered radiation accounts for approximately $50 \%$ of the total dose received. Comparisons were made with doses calculated by a method suggested by Clarkson together with the depth dose data. Reasonable agreement was found. 


\section{INTRODUCTION}

In order to understand the effects of radiation on an irradiated medium, the spectral distribution of the radiation at the point in question is required. The radiation reaching a point within an irradiated medium consists of primary radiation which reaches the point without interaction and the scattered radiation which has undergone one or more Compton scatterings. The scattered radiation will, in general be incident on the point from all directions and the spectral distributions will be different in each direction. For most applications of spectral information in radiological physics the direction of incidence of the radiation is immaterial. Such applications include calculations of absorbed dose, ionization in a small cavity and distribution of Iinear ion density or LET. All that is required in these cases is the spectral distribution integrated over all angles. As an illustration consider the calculation of absorbed dose. Suppose that the spectral distribution incident at some point with photon energy $k$ (KeV) at angle $\vec{\Omega}$ is $N(k, \vec{\Omega})$ photons per $\mathrm{cm}^{2}$ per steradian per photon energy interval (KeV). The area is always taken perpendicvalar to $\vec{\Omega}$. Let $\mu_{\mathrm{m}} \mu_{Q}(k)$ be the real absorption coefficient of the material in $\mathrm{cm}^{2}$ per $\mathrm{g}$. Then the energy absorbed in the material from photons incident at angle $\vec{\Omega}$ is $\mathrm{k} \cdot \mathbb{N}(\mathrm{k}, \vec{\Omega}) \cdot{ }_{\mathrm{HI}} \mu_{\mathrm{a}}(\mathrm{k}) \mathrm{KeV}$ per $\mathrm{g}$ per steradian per KeV. The energy absorbed from photons travelling in all directions is

$$
\int_{\Omega} k \cdot N(k, \vec{\Omega})_{m} \mu_{a}(k) d \vec{\Omega}=k \cdot{ }_{m} \mu_{a}(k) \quad \int_{\Omega} N(k, \vec{\Omega}) d \vec{\Omega} .
$$

The integral on the right hand side of the equation represents simply the spectrum integrated over all angles. 
With a scintillation spectrometer of the total-absorption type one can measure the spectrum of the radiation incident on a small area $\triangle A$ within a small solid angle $\Delta \Omega$ where $\triangle A$ and $\Delta \Omega$ are determined by the geometry of the collimating system. That is, one measures a quantity proportional to $N(k, \vec{\Omega})$ at a number of angles and at a number of photon energies. Most of the measurements up to the present time (1-4) have been made for points on the central axis of a circular beam of radiation with an apparatus which could be rotated only about an axis at right angles to the beam. If one represents the angle between the Incident beam and the measured scattered beam by $\theta$ and the angle of rotation about the beam axis by $\varphi$ (see Fig. I) one can write the integrated spectra as

$$
N(k)=\int_{\Omega} N(k, \vec{\Omega}) d \vec{\Omega}=\int_{0}^{\pi} \int_{0}^{2 \pi} N(k, \vec{\Omega}) \sin \theta d \varphi d \theta .
$$

However, for the central axis of a circular field $N(k, \quad)$ does not depend on $\varphi$ and, therefore

$$
N(k)=\int_{0}^{\pi} 2 \pi \sin \theta N(k, \vec{\Omega}) d \theta .
$$

In the present investigation the apparatus has been designed so that both $\theta$ and $\varphi$ may be varied. With this apparatus it is possible to obtain integrated spectra for points where there is no radial symmetry. This thesis reports measurements of the spectral distributions of scattered radiation at points inside and outside the boundary of a circular beam of X-rays for two different qualities, $280 \mathrm{KVP}$, HVL $2.5 \mathrm{~mm}$ of $\mathrm{Cu}$ and $140 \mathrm{KVP}$, HVL $1.45 \mathrm{~mm} \mathrm{Al}$. The spectral distribution of scattered radiation at the central axis of the beam was also measured for comparison purposes. 
II. APPARATUS

The apparatus used is basically the same as that described by T.J. Griffith (I) and is shown in Fig. I. The apparatus consists of a lucite tank $45 \mathrm{~cm}$ in diameter and $30 \mathrm{~cm}$ long mounted on a steel frame. Various amounts of water can be put into the tank. A small lucite tube with a closed end is mounted midway between the ends of the tank and extends from the centre axis of the tank to the curved surface. A shutter with a $1 / 2$ " hole in the middle is mounted outside the tank and followed by a collimating system and a housing for the detecting system. The shutter is incorporated to facilitate the background counting. To measure the background, the shutter is replaced by a solid lead block so that photons passing through the lucite tube will not reach the detecting system. A hole is drilled through the shielding to admit a beam of radiation for calibration purposes. The whole apparatus, including the cylinder, can be rotated about the axis of the cylinder in order to vary the angle $\theta$.

The apparatus described above may be used for measurements at points on a vertical axis of radial symmetry but must be modified for less symmetrical geometries. Such a modification was accomplished as follows:

On the steel frame, a small piroted screw jack was mounted directly below the end of the lucite tube. In actual measurements, the whole apparatus is raised slightly so that it is pivoted by the screw jack. Most of the weight of the apparatus is carried by the 


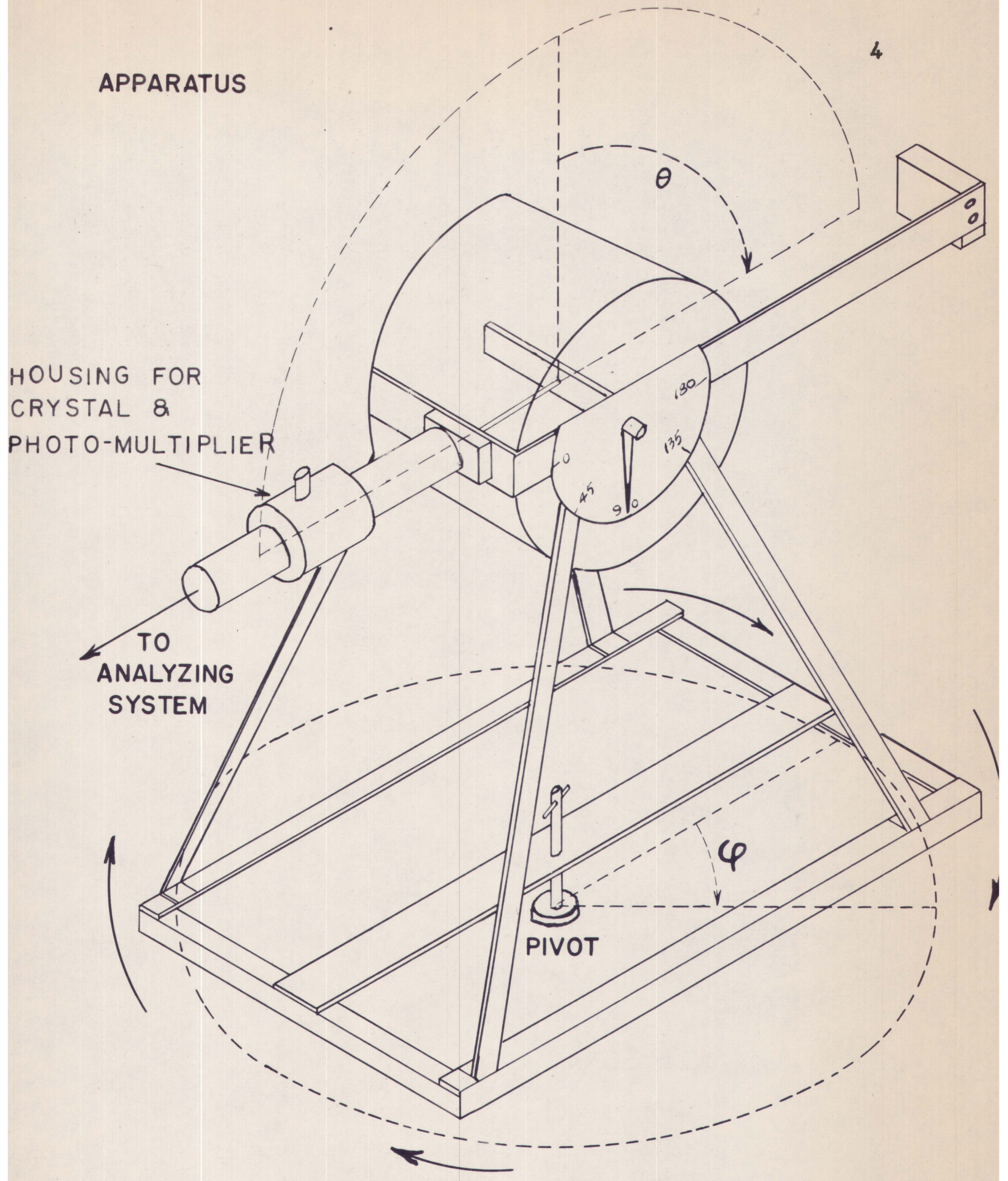

FIGURE I 
pivot while the four casters keep it from tilting. This enables the apparatus to be rotated about a vertical axis through the end of the Incite tube.

In Fig. I, the scattering angle and azimuthal angle are defined. The scattering angle, $\theta$, is defined as usual, that is, the angle between the direction of incident photon and that of the scattered photon. The scattering angle, $\theta$ is zero when the direction of both 1s the same. The azimuthal angle is the angle produced by rotating the whole apparatus about the vertical axis through the centre of the tank. $\varphi$ is zero when the lucite tube sees a minimum amount of irradiated field as shown in Fig. II.

Photons striking the end of the lucite tube were collimated and then incident on a $2^{n}$ diameter and $15 / 8^{n}$ long $N a I(T I)$ crystal. The crystal had a very thin window, $0.001^{\prime \prime} \mathrm{Al}$ and was obtained from Harshaw Company. The collimating system was such that only a portion of the photons striking the end of the lucite tube was accepted. The light pulses produced in the crystal by the photons were detected by a Dumont Kl234 10-stage photomultiplier. A positive high viltage of about 1000 volts, obtained from a Baird-Atomic Model 312 power supply, was supplied to the anode of the photomultiplier with the cathode at ground potential. The output pulse was coupled to a $6 \mathrm{~J} 6$ cathode follower for impedance matching. The output, having been amplified by a Baird-Atomic Model 204-B Iinear amplifier, was fed to a Baird-Atomic Model 510 pulse height analyzer, and then to a Baird-Atomic Model $131 \mathrm{~A}$ scaler. A block diagram of the whole system together with clrcuit diagram of 


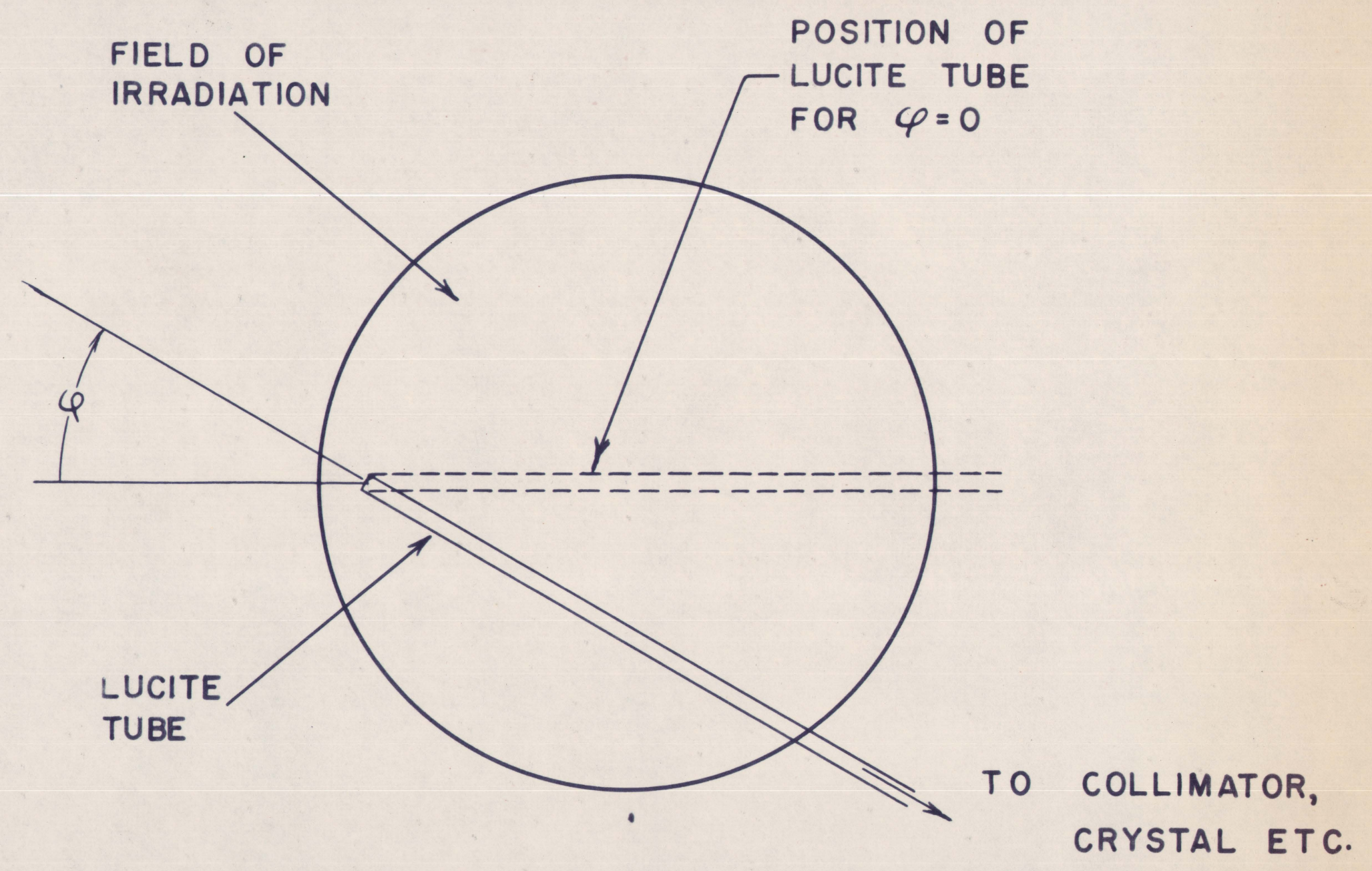

FIGURE II 
cathode follower is shown in Fig. III.

Using the apparatus described, the spectra of scattered radiation at the centre and at the points $1.47 \mathrm{~cm}$ inside and $1.88 \mathrm{~cm}$ outside the boundary of a $100 \mathrm{~cm}^{2}$ eireular field at a focal skin distance (the distance between the target and the surface of the water) of $60 \mathrm{~cm}$ were measured. Measurements were carried out at $5.0 \mathrm{~cm}$ depth for $280 \mathrm{KVP} X$-rays, and at $2.0 \mathrm{~cm}$ depth for $140 \mathrm{kVP}$ X-rays. Both kinds of radiation were obtained from a Picker Vanguard machine in the Saskatoon Cancer Clinic. 


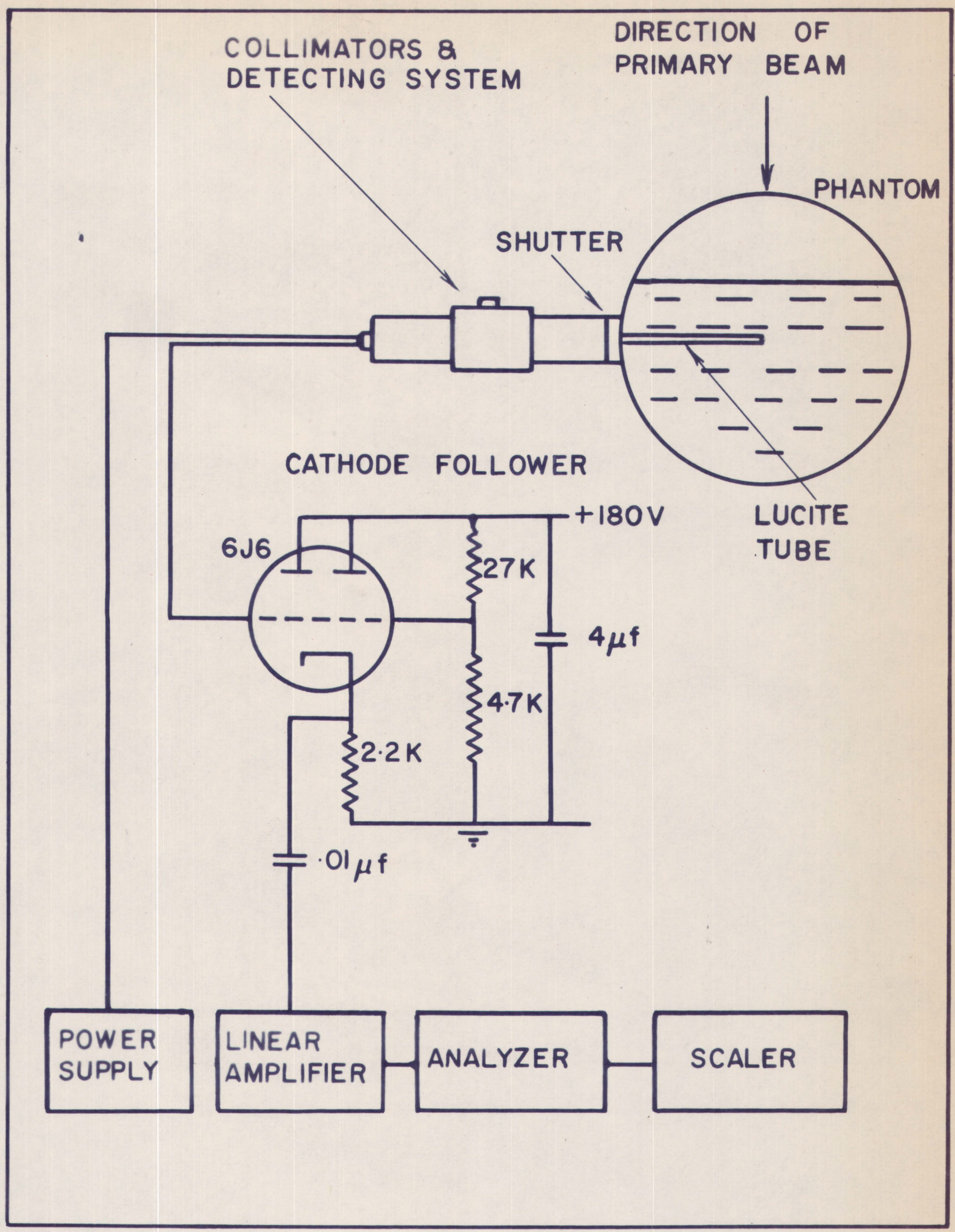




\section{CALIBRATION}

A calibration curve is necessary to convert the base line voltage readings on the pulse height analyzer into photon energy units (KeV). The gamma-rays from $\mathrm{Ba}^{133}$ and $\mathrm{K}$-characteristic $\mathrm{X}$-rays from various materials were used as energy calibration sources. Bal33 emits two gamma-rays of 79 and $355 \mathrm{KeV}$. The gain of the amplifier was adjusted so that the centre of the $355 \mathrm{KeV}$-peak was obtained at a base line setting on the analyzer of $60 \mathrm{v}$ using a channel width of 2 volts. Then the base line roltage setting corresponding to the $79 \mathrm{KeV}$ gammray was recorded.

To obtain the characteristic X-rays of various materials, the materials were bombarded by X-rays from a General Electric Maximar machine and the $\mathrm{K}$-characteristic $\mathrm{X}$-rays from these materials were detected by the NaI(TI) crystal at approximately 90 degrees from the incident beam (See Fig. IV).

Since $\mathrm{Ka}_{I}$ line has a greater intensity than $\mathrm{Ka}_{2}$ line, approximately 3 to 1 , the energy of the $\mathrm{Ka}_{1}$ line was used as $\mathrm{K}$-characteristic $X$-ray energy of the various materials.

A list of materials used in the experiment together with their $\mathrm{K}$-characteristic $\mathrm{X}$-ray energies (5) and corresponding base line voltage setting is shown in the following table. 
TABLE I: MATERIAIS USED FOR CAIIBRATION

\begin{tabular}{lcc} 
Material & $\begin{array}{c}\text { Characteristic } \\
\text { X-Ray Energy } \\
(\mathrm{KeV})\end{array}$ & $\begin{array}{r}\text { Base Line } \\
\text { Voltage }\end{array}$ \\
\hline Zirconium & 15.8 & 1.45 \\
Tin & 25.3 & 3.30 \\
Barium & 32.2 & 4.52 \\
Cerium & 34.7 & 4.96 \\
Tungsten & 59.3 & 9.30 \\
Lead & 75.0 & 12.22 \\
& & \\
& $\gamma-\mathrm{Rajs}$ & \\
Bal33 & $(\mathrm{KeV})$ & 13.3 \\
Bal33 & 79 & 60.0 \\
& 355 &
\end{tabular}

The Calibration curve so obtained is shown in Fig. V. It can be seen that the curve is nearly linear except near the low energy end. The curvature of this curve will be discussed in a later section (see Treatment of Data). 


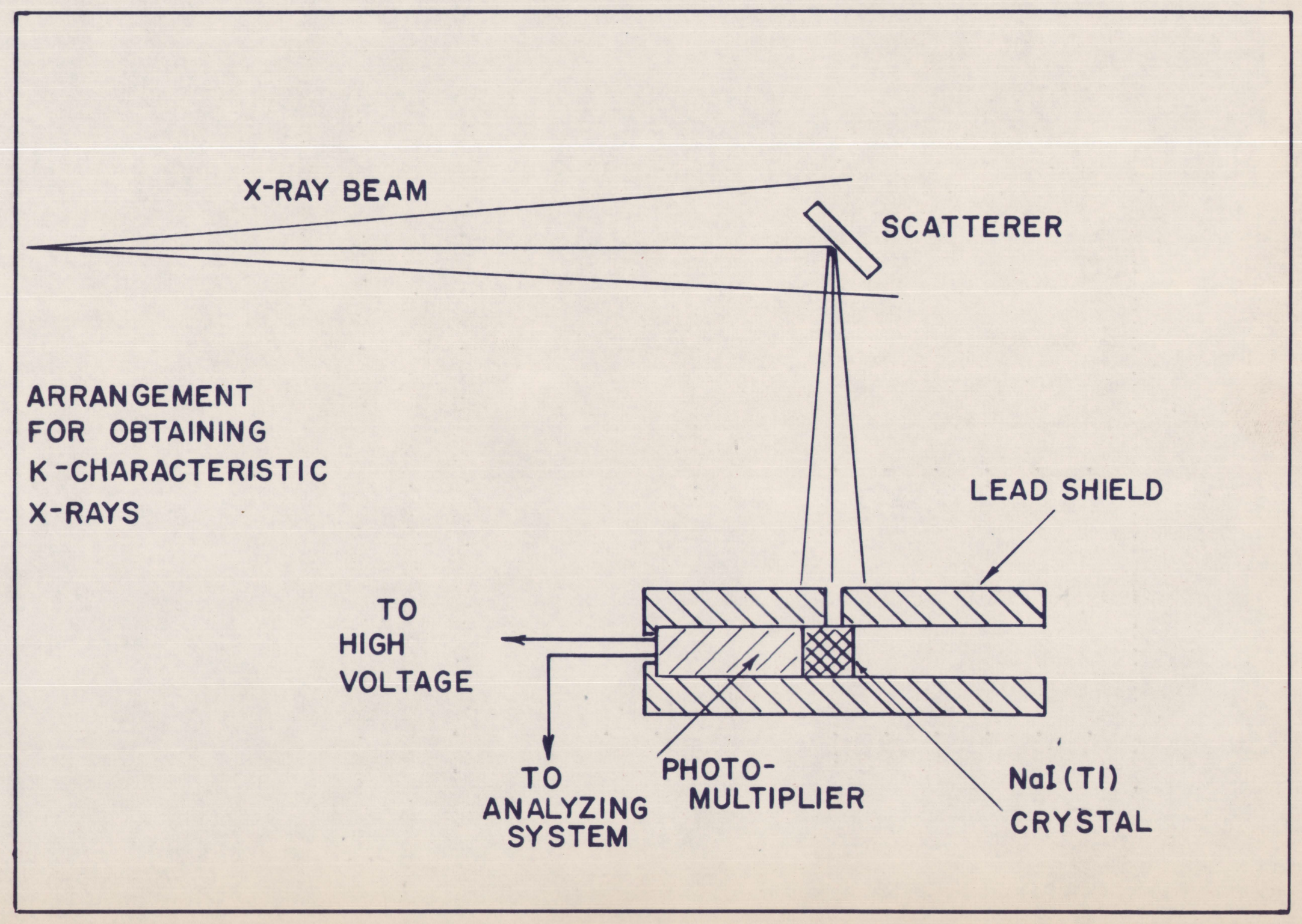




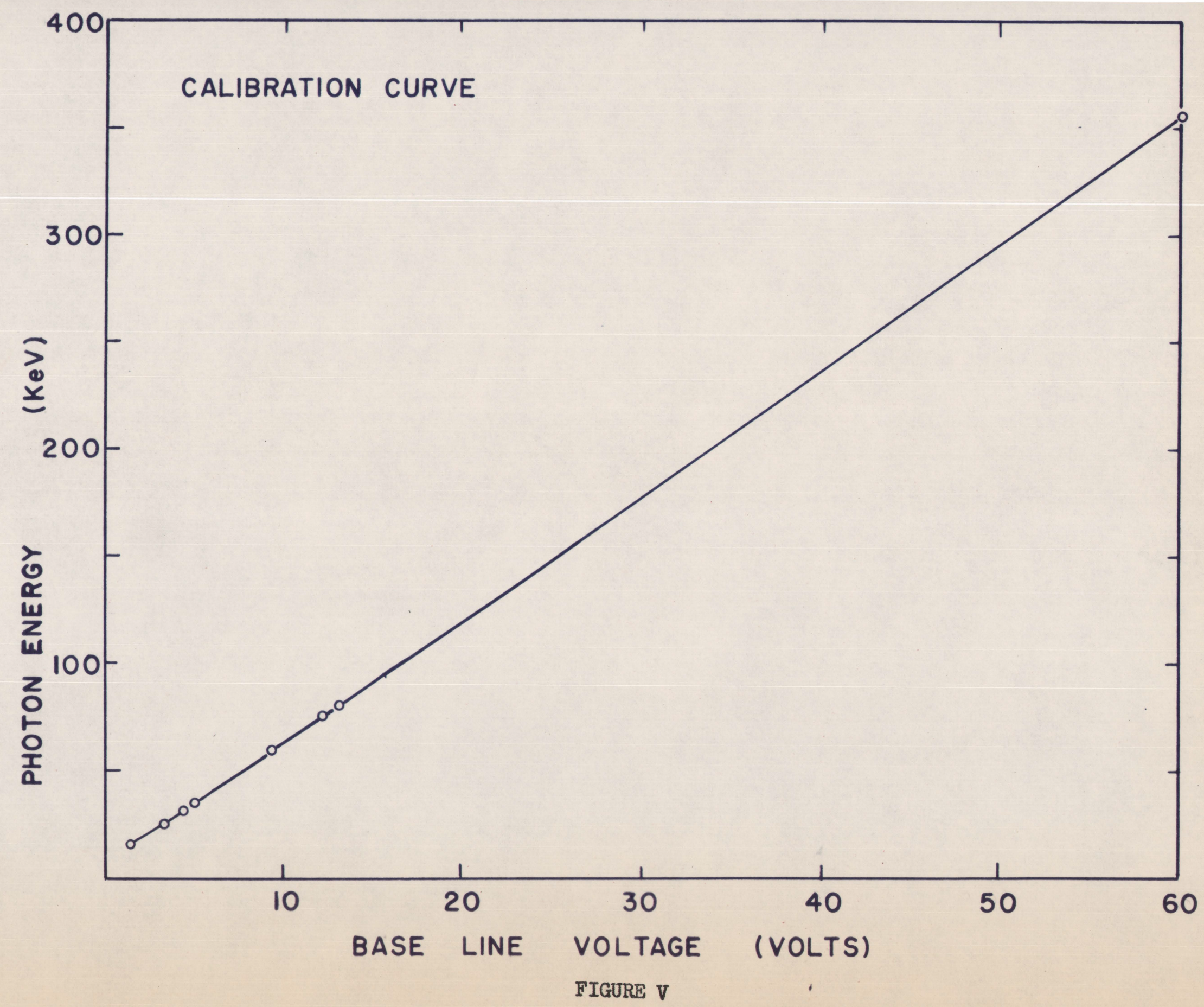




\section{METHOD OF ALIGANENT}

It is very important especially for the points near the boundary of the field to position the apparatus correctly. At first, the head of the X-ray machine was adjusted so that the beam was directed vertically dowmward. The apparatus was moved under the machine and the height of the latter was adjusted to give the desired focal skin distance, in this case, $60 \mathrm{~cm}$. It was now necessary to position the apparatus so that the end of the lucite tube was at the geometrical centre of the beam. The positioning for the central axis point was done as follows:

The apparatus was moved away and a plumb-bob was hung from the centre of the diaphragm which limited the size of the field. The position of the plumb-bob was marked on the floor. Then the apparatus was positioned so that the pirot point coincided with the "mark" on the floor (see Figs. I and VI), Since the pirot is directly below the end of the lucite tube, this positioning would place it at the centre of the beam.

It was found oarlier, by exposing an X-ray film in the beam that the field had a rather large and non-symmetrical penumbra. In order to see the effect of the irregular penumbra on the scattered spectra from different directions in a horizontal plane, spectra were measured for various azimuthal angles $\varphi$. It was found that these spectra had nearly the same shape and maitude. This confirms our assumption that the radiation is radially symmetrical for the central axis point. 


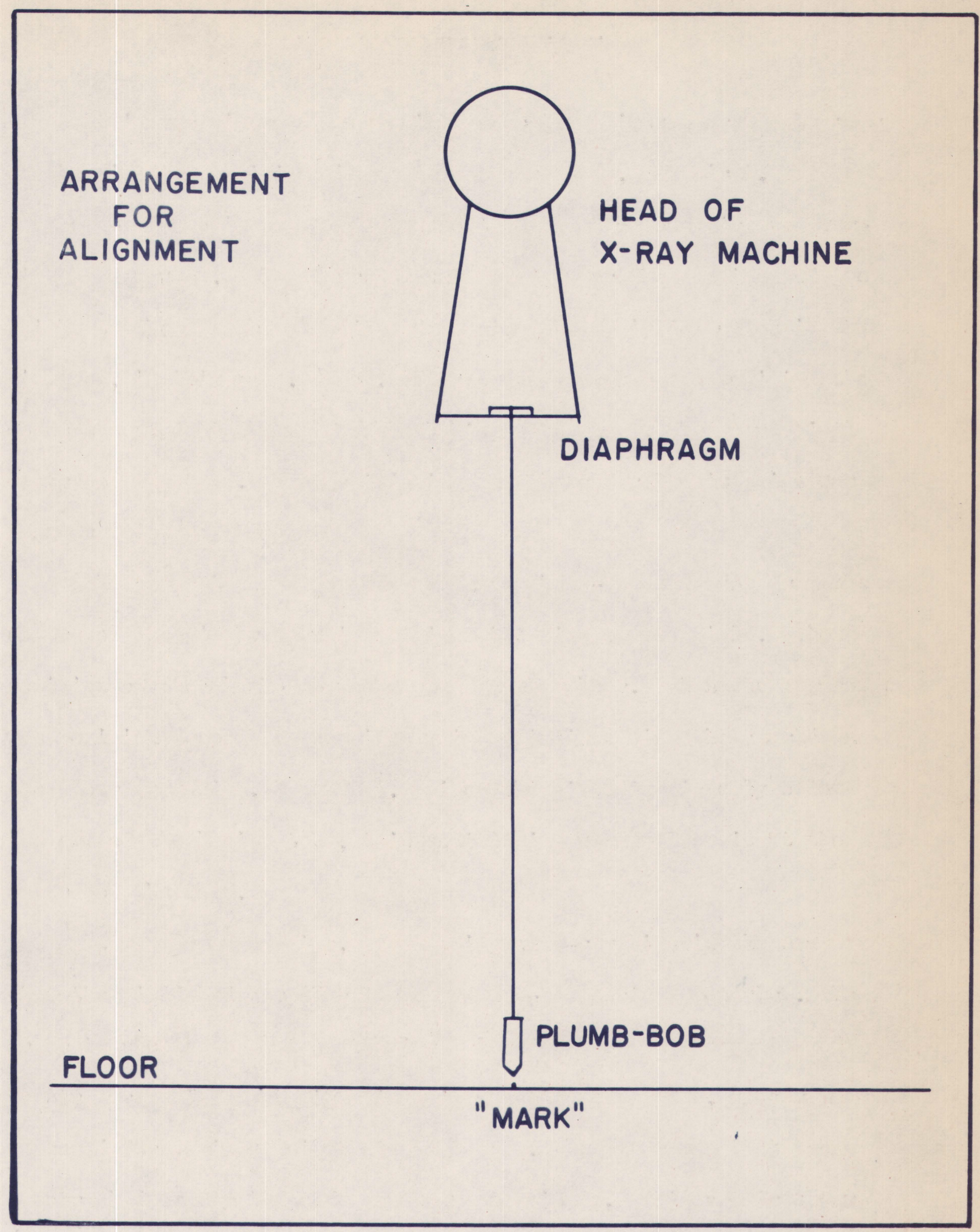

FIGURE VI 
Although the penumbra effect can be disregarded in the measurement of scattered radiation at the central axis, it cannot be overlooked for the points near the boundary. If the measurements were taken near the edge where the penumbra is greatest, the results would be erroneous. For instance, a point outside the boundary is actually Inside the penumbra. The penumbra effect was minimized by choosing the part of the boundary where it is least and by using a trial and error method as follows:

After the position of the plumb-bob was marked on the floor, the pirot on the apparatus was made to coincide with a point at an appropriate distance away from the "mark" on the floor. Then the apparatus was orientated by geometry so that the lucite tube saw a minimum amount of the field. This would correspond to $\varphi=0$ if the pemumbra did not exist. From the geometry of the system it can be seen that the spectrum at $\varphi=90^{\circ}$ should be the same as that at $\varphi=270^{\circ}$. This fact was used to orientate the apparatus to conform to the definition. For a fixed scattering angle $\theta$, say $90^{\circ}$, the spectrum at $\varphi=90^{\circ}$ was taken. Then the apparatus was rotated $180^{\circ}$ and another spectrum was taken. If both spectra were identical, the $\varphi$ orientation would be correct. If, however, they differed, a spectrum at a new $\varphi$ value, slightly different from $90^{\circ}$, say $95^{\circ}$, was taken and compared with that obtained at $275^{\circ}$. This process was repeated until an orientation such that both spectra were nearly identical. Then a correction was applied to the zero reading on the $\varphi$ scale. The above procedure also corrected for the non-uniformity of the field near the point in question. 
To ensure the point outside the boundary was indeed outside the Irradiated area, a Baldwin-Farmer sub-standard dosimeter was used to detect the amount of radiation at the point in question with the $X$-ray machine turned on before the apparatus was in its place. It was found that when the dosimeter was placed outaide the expected boundary, the reading was very small indicating that the point was indeed outside the primary beam. 
V. PROCEDURE

After the apparatus was correctly orientated, field area and depth of water were properly set, spectra were taken for $\theta=50^{\circ}$, $70^{\circ}, 90^{\circ}, 120^{\circ}$ and $135^{\circ}$ for each value of $\varphi$. Spectra were measured at $\varphi=0^{\circ}, 45^{\circ}, 90^{\circ} .735^{\circ}$ and $180^{\circ}$. For the central point, spectra at $\theta=18^{\circ}, 30^{\circ}, 60^{\circ}, 90^{\circ}, 120^{\circ}$ and $135^{\circ}$ were taken.

In order to obtain a spectral distribution, the base line roltage setting on the pulse height analyzer was varied and the counts for fifteen seconds at each base line voltage setting were taken. The channel width was set constant at 2 volts throughout the whole experiment.

Background readings were taken with the shutter replaced by a solid lead block and the X-ray machine turned on. It was found that the background was nearly the same whether the X-ray machine was on or off indicating that the system was well-shielded. Background readings were negligible above $45 \mathrm{KeV}$.

The long term stability of the spectrometer was very good; however, the calibration was checked every hour or so by testing if the $355 \mathrm{KeV}$ gamma-ray from Ba 733 would still give a 60 volt base line reading. If it was found that it had drifted, the gain of the linear amplifier was adjusted until the peak appeared at 60 volts.

For the $280 \mathrm{KVP} X$-rays, the output of the machine was quite constant; however, for the $140 \mathrm{KVP}$, it was found that the output varied slowly. To correct for this variation, a large ionization 
chamber was inserted between $X$-ray target and the phantom. The Ionization chamber was connected to a monitor circuit which would give an indication of ionization current. All the readings would be normalized to an arbitrary monitor reading.

Some of the spectra with background subtracted are shown in Figs. VIIa and VIIb. 


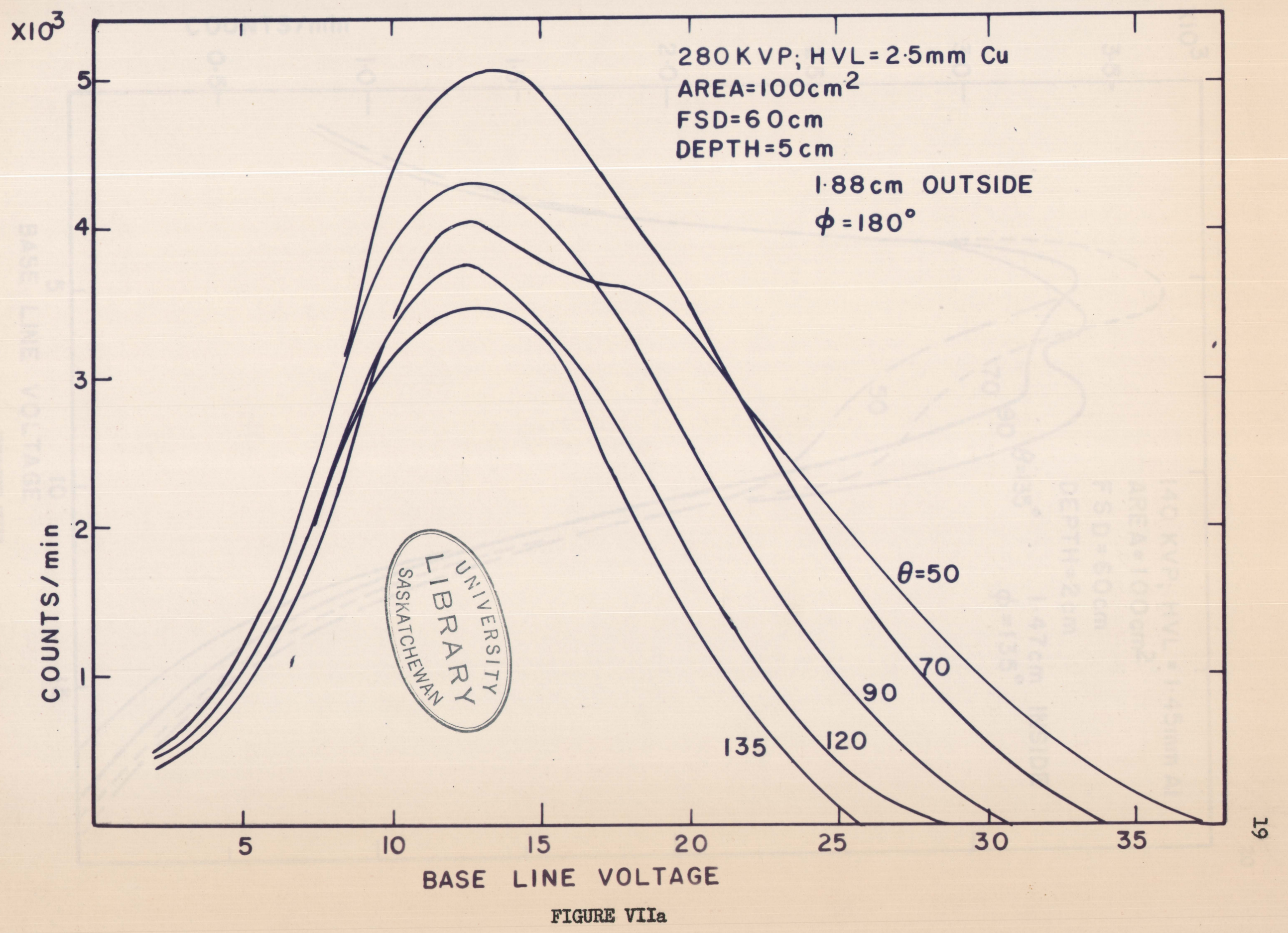




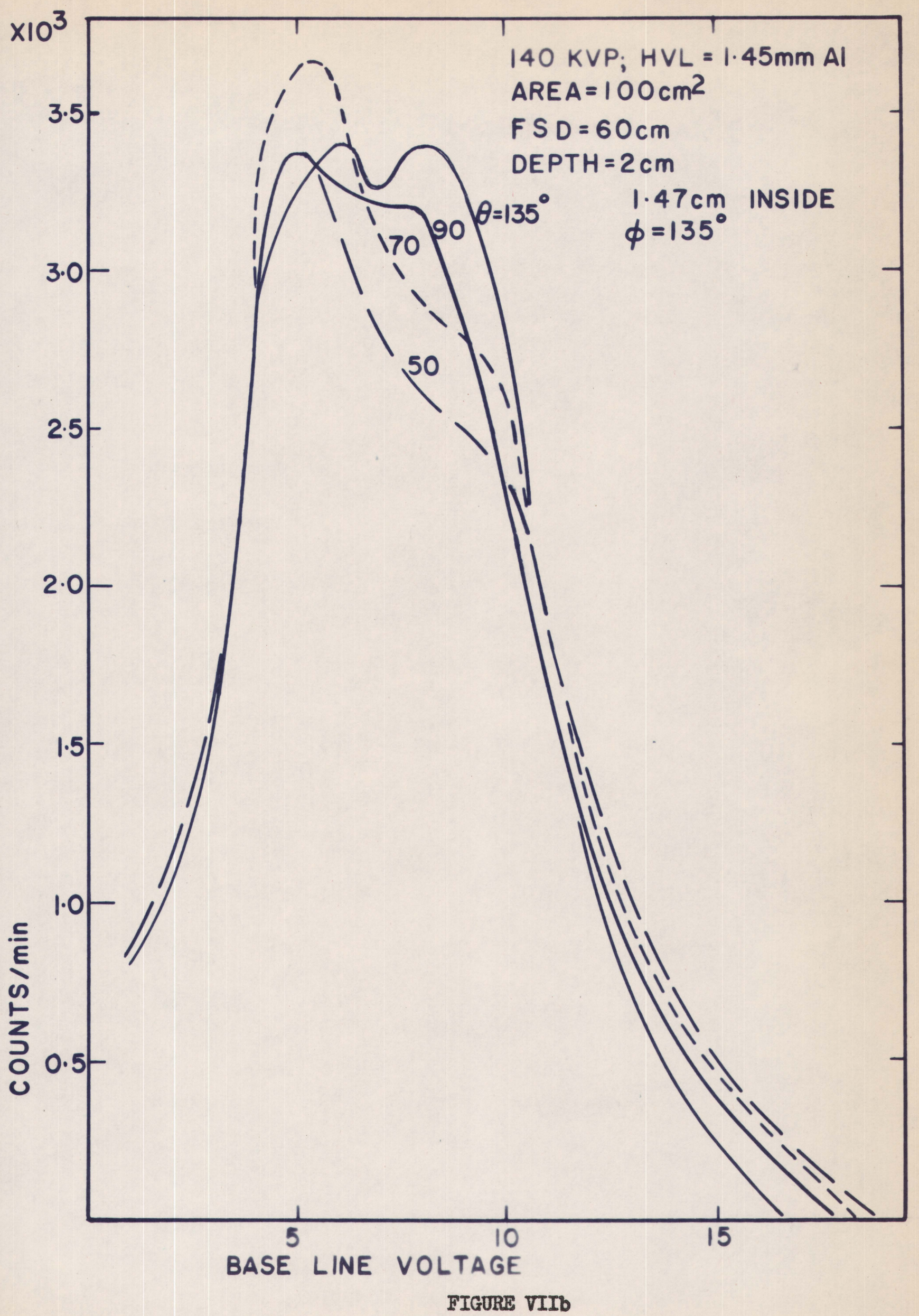


VI. TREATMENT OF DATA

The spectra were converted from base line voltage to energy units (KeV) by a calibration curve. It was noted that the calibration curve was not a straight line, but slightly curved at the low energy end. The ordinates of the measured spectra were in units of relative counts per second per unit channel width. The non-linearity of the calibration curre effectively changes the size of the hoton energy interval per unit channel width. Therefore, it was necessary to correct for the difference of slope in the calibration curve. The calibration curve was divided into intervals and the slopes at the mid-points of these intervals were measured. The slope was assumed to be constant throughout any interval and all the ordinate readings In the spectra vere normalized to the slope at $355 \mathrm{KeV}$. Table II shows the slope and correction factors.

TABLE II: CORRECTION FACTORS

FOR NON-LINEARITY OF CALIBRATION CURVE

\begin{tabular}{lc}
$\begin{array}{l}\text { Energy } \\
\begin{array}{l}\text { Range } \\
(\mathrm{KeV})\end{array}\end{array}$ & $\begin{array}{c}\text { Correction } \\
\text { Factor }\end{array}$ \\
\hline $15-55$ & 1.13 \\
$65-85$ & 1.11 \\
$95-105$ & 1.08 \\
$115-155$ & 1.05 \\
165 and up & 1.00
\end{tabular}


The spectra were then corrected for the limited resolution of the photomultiplier tube by an approximate method (6). The effect of this correction was an increase of the peak height of a spectrum with a decrease at both ends. This would be expected since this correction was the reverse of Gaussian spreading. In a Gaussian spreading some of the photons from the peak would appear at energies higher or lower than the peak energy. So the reverse would show an increase in peak height.

The spectra were then corrected for loss of energy from the crystal. This correction had been discussed fully in a paper by Rawson and Cormack (7). The $20 \mathrm{KeV}$ intervals in the matrix worked out by Rawson and Cormack were not fine enough for this work. Therefore, a similar matrix with $10 \mathrm{KeV}$ intervals was constructed for this correction. For these energies most of the energy loss is due to the escape of lodine $\mathrm{X}$-rays.

After these corrections a double integration, over $\varphi$ and $\theta$, was performed to obtain the integrated spectrum for each point in question. The integration over all $\varphi$ was performed first. This was done by plotting the relative number of counts per 15 seconds against angle $\varphi$ while energy and scattering angle $\theta$ were held constant. This plotting produced families of curves. A few of these curves are shown in Fig. VIII. The integration was performed by measuring the areas under them with a planimeter. The values of areas would give $\int_{0}^{2 \pi} N(k, \vec{\Omega}) d \varphi$ where $N(k, \vec{\Omega}) d \varphi$ is the number of photons with a particular energy at a particular scattering angle, $\theta$ with azimathal 


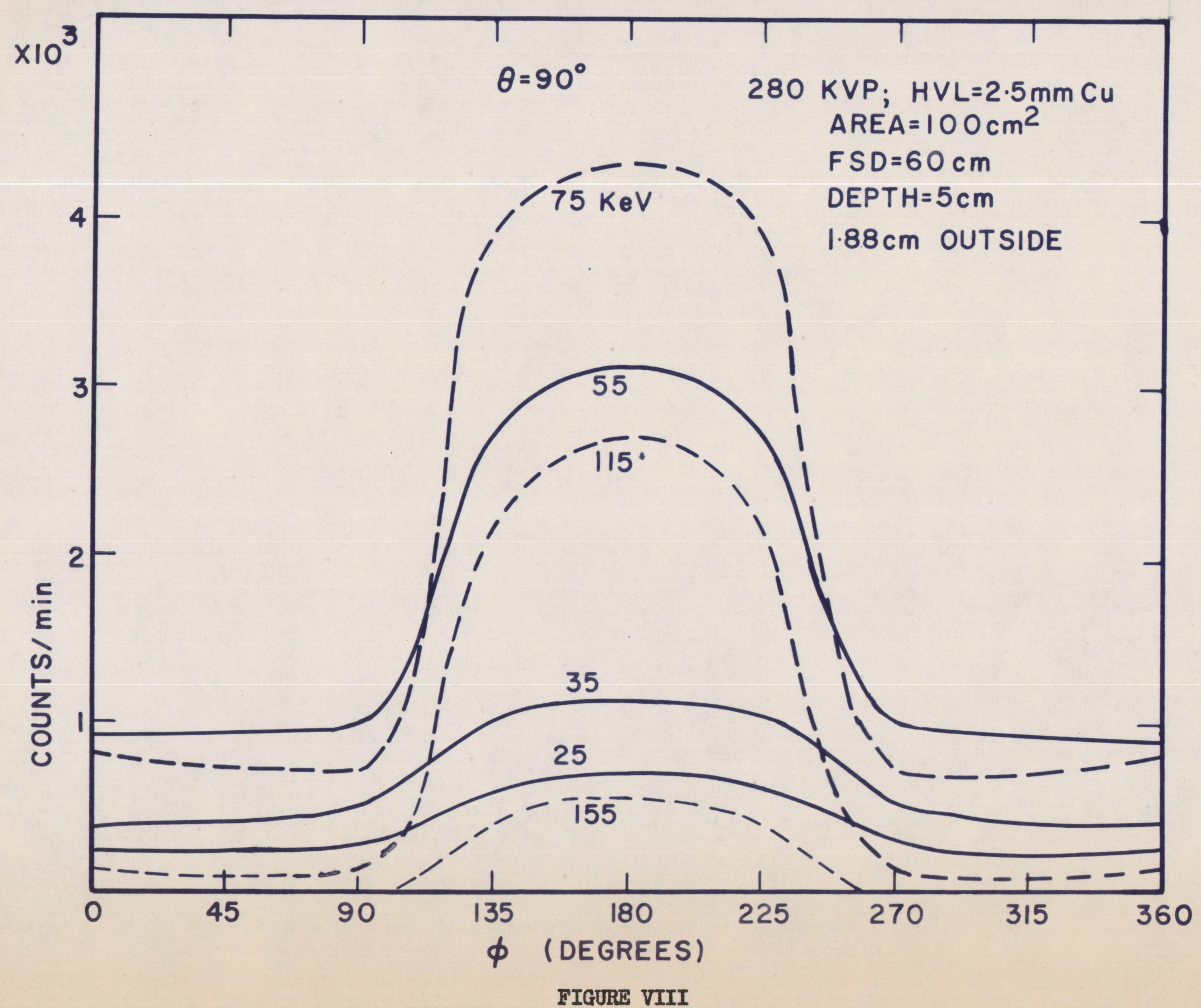


angles between $\varphi$ and $\varphi+\mathrm{d} \varphi$. The integration over $\theta$ was done by multiplying $\int_{0}^{2 \pi} N(k, \vec{\Omega}) d \varphi$ by $\sin \theta$, plotting against $\theta$ as shown in Fig. IX and measuring the enclosed areas with a planimeter. These values would give $\int_{0}^{\pi} \int_{0}^{2 \pi} N(k, \vec{\Omega}) \sin \theta d \varphi d \theta$, photons scattered from all directions.

Since the radiation is independent of $\varphi$ for the point on the central axis, the integration over $\varphi$ was done simply by multiplying by $2 \pi$. Other than this difference, the procedure in treating the data was the same as described above.

The fully integrated spectra are shown in Figs. $X_{a}$ and $X b$ and are tabulated in Table III. 
TABLE III: SCATTERED SPECTRA

$$
\text { F.S.D. }=60 \mathrm{~cm}, \text { Area }=100 \mathrm{~cm}^{2}, \mathrm{~N}(\mathrm{k})=\text { No. of Photons } / \mathrm{cm}^{2} / \mathrm{sec} / \mathrm{KeV}
$$

\begin{tabular}{|c|c|c|c|c|c|c|}
\hline \multirow[b]{2}{*}{$\begin{array}{r}\text { Photon } \\
\text { Energy } \\
(\mathrm{KeV})\end{array}$} & \multicolumn{3}{|c|}{$280 \mathrm{kVP}$, Depth $=5 \mathrm{~cm}$} & \multicolumn{3}{|c|}{$140 \mathrm{KVP}$, Depth $=2 \mathrm{~cm}$} \\
\hline & $\begin{array}{c}\text { Centre } \\
\mathrm{N}(\mathrm{k})\end{array}$ & $\begin{array}{l}1.47 \mathrm{~cm} \\
\text { Inside } \\
\mathrm{N}(\mathrm{k})\end{array}$ & $\begin{array}{c}1.88 \mathrm{~cm} \\
\text { Outside } \\
\mathbb{N}(\mathrm{k})\end{array}$ & $\begin{array}{l}\text { Centre } \\
\mathrm{N}(\mathrm{k})\end{array}$ & $\begin{array}{c}1.47 \mathrm{~cm} \\
\text { Inside } \\
\mathrm{N}(\mathrm{k})\end{array}$ & $\begin{array}{c}1.88 \mathrm{~cm} \\
\text { Outside } \\
\text { N(k) }\end{array}$ \\
\hline 25 & 187 & 73 & 88 & 622 & 500 & 62 \\
\hline 35 & 715 & 502 & 395 & 2138 & 1733 & 472 \\
\hline 45 & 1700 & 1427 & 843 & 1712 & 1378 & 445 \\
\hline 55 & 3280 & 2520 & 1354 & 1514 & 1294 & 411 \\
\hline 65 & 4380 & 3165 & 1727 & 818 & 824 & 220 \\
\hline 75 & 4670 & 3420 & 1708 & 359 & 338 & 104 \\
\hline 85 & 4300 & 3185 & 1474 & 186 & 158 & 40 \\
\hline 95 & 3521 & 2510 & 1172 & 50 & & \\
\hline 105 & 2805 & 2028 & 1027 & & & \\
\hline 215 & 2080 & 1469 & 733 & & & \\
\hline 125 & 1589 & 1088 & 555 & & & \\
\hline 135 & 1152 & 802 & 370 & & & \\
\hline 145 & 848 & 577 & 270 & & & \\
\hline 155 & 662 & 427 & 181 & & & \\
\hline 165 & 359 & 302 & 101 & & & \\
\hline 175 & 251 & 214 & 78 & & & \\
\hline 185 & 189 & 110 & 39 & & & \\
\hline
\end{tabular}




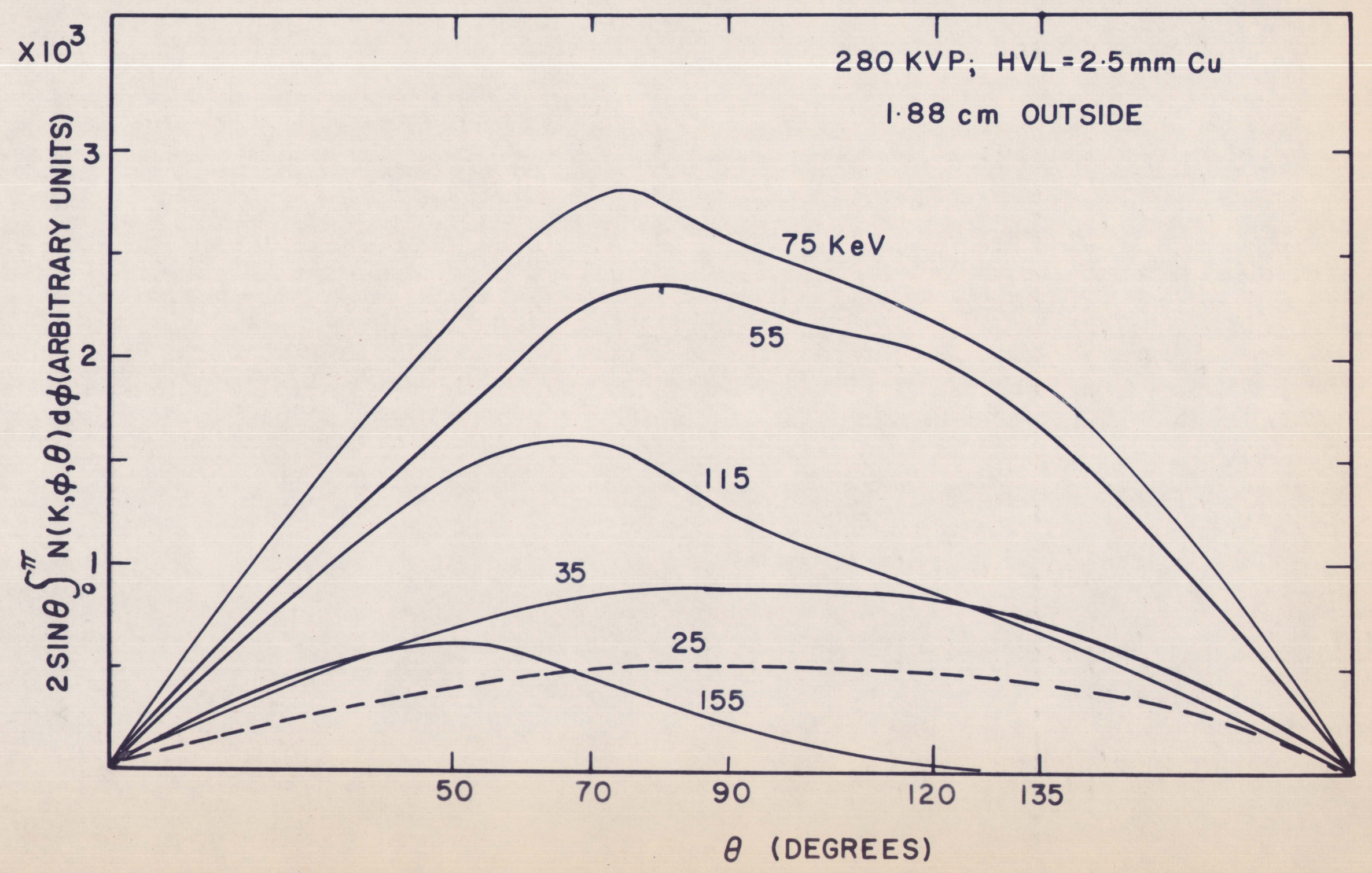




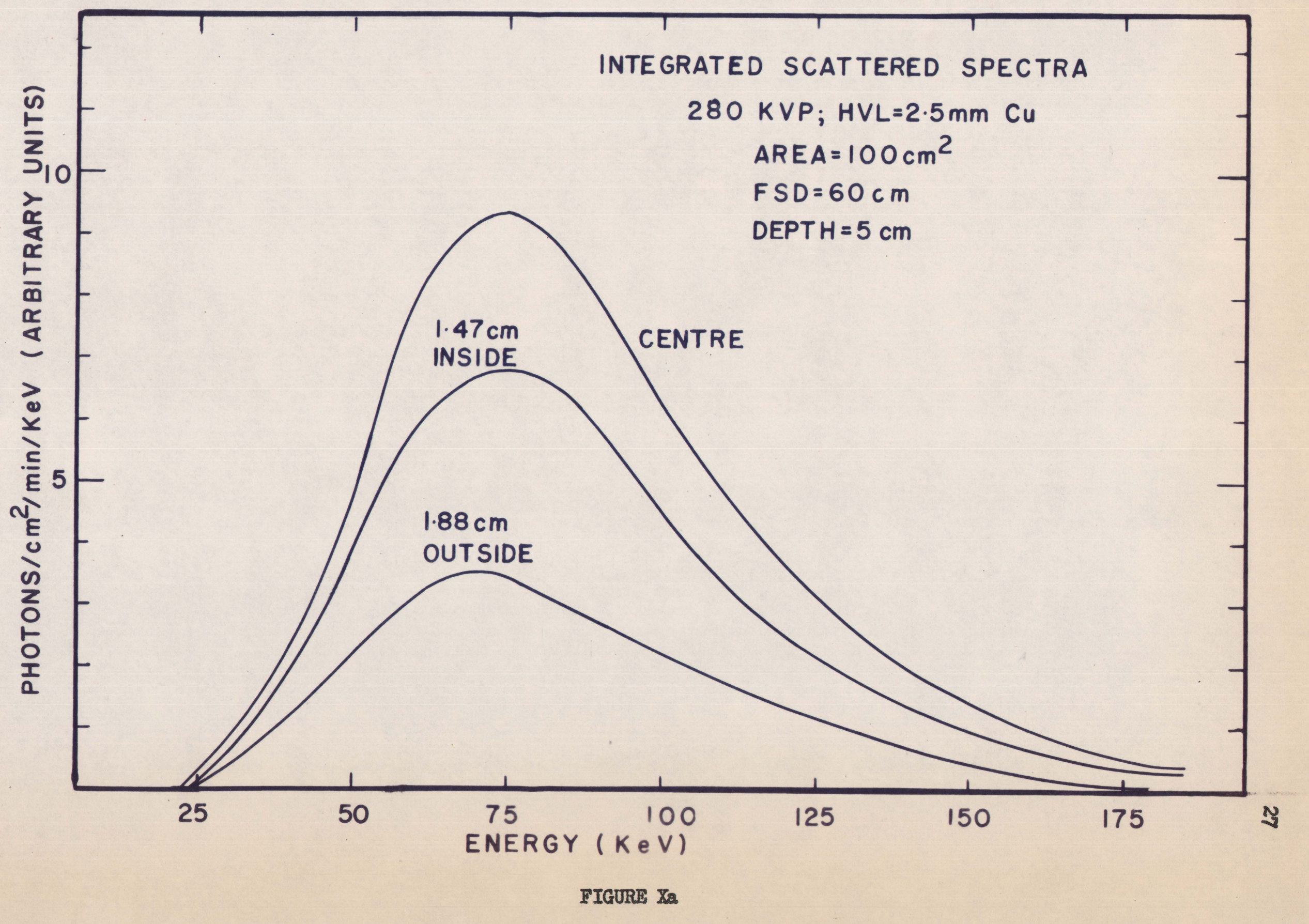




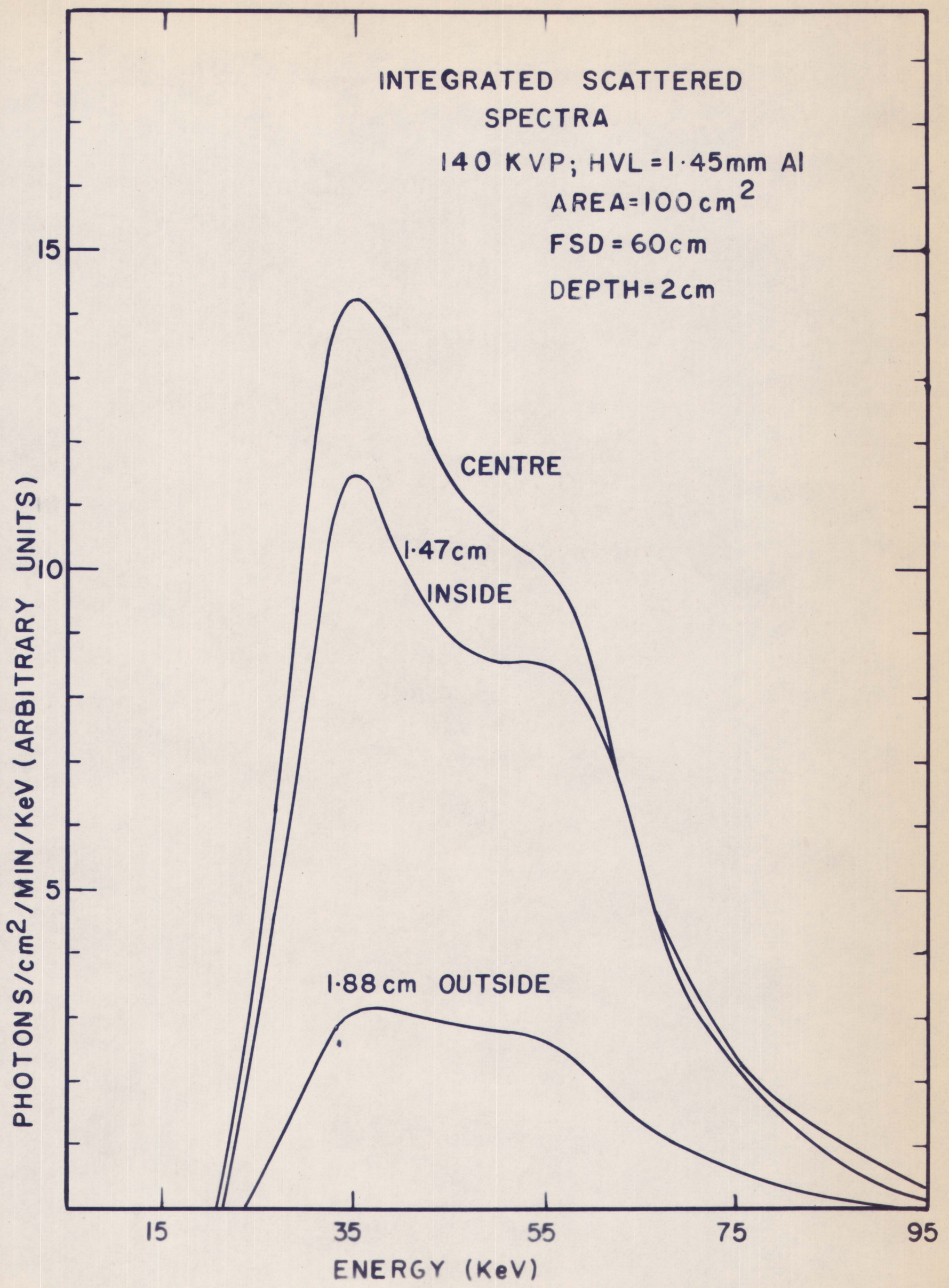

FIGURE Xb 


\section{DISCUSSION OF RESULTS}

\section{A. General}

The following discussion applies to both $280 \mathrm{KVP}$ and $140 \mathrm{KVP}$ radiation. For the points outside the irradiated field the spectra appear to be nearly independent of scattering angle $\theta$, for $\varphi=0^{\circ}$, $45^{\circ}$ and $90^{\circ}$. The curves for different $\theta$ would fall on top of each other and so have not been plotted. The radiation spectrum appears to be independent of $\varphi$ also from $\varphi=0^{\circ}$ to $\varphi=90^{\circ}$. Fig. VIII shows the counting rate at various energies plotted against $\varphi$ for $\theta=90^{\circ}$. In view of the above observations, all radiation scattered in from outside the field appears to be independent of direction. As seen in Fig. VIII the counting rate increases sharply between $\varphi=90^{\circ}$ and $135^{\circ}$. There probably is a discontinuity at the point where the spectrometer begins to accept radiation from the irradlated field. In Fig. VIII it should be pointed out that only the

portions of the curves from $\varphi=0^{\circ}$ to $\varphi=180^{\circ}$ were actually measured, the rest of the curves being obtained by reflection about $\varphi=180^{\circ}$.

\section{B. $280 \mathrm{KVP}$}

As seen in Fig. Xa the shapes of the integrated spectra inside the field, outside the field and at the centre were nearly the same, except that the peak for the point outside is shifted slightly towards the lower energy end. It will be noted that there is a large decrease 
in the amount of scattered radiation as the boundary of the field is crossed.

In order to determine the dose received at the various points, the relative number of photons per $\mathrm{cm}^{2}$ per sec per $\mathrm{KeV}$ was converted into roentgens per sec per $\mathrm{KeV}$, plotted against energy and then integrated over all energies. It was found that the dose at $1.47 \mathrm{~cm}$ inside the field was $73 \%$ of that received at the centre and at $1.88 \mathrm{~cm}$ outside, $37 \%$ of that at the centre.

Doses received at the points off the beam axis were calculated by a method put forth by Clarkson ( 8 ) and using the depth dose data of Johns et al (9). This method involves dividing the irradiated area into sectors with the point in question as common origin. The mean radius of each sector is measured. The contribution of scattered radiation from each sector is equal to $\frac{\Delta \omega}{360}$ of the scattered radiation from a circular field of the same radius where $\Delta \omega$ is the size of the sector in degrees. By adding up the contributions from all sectors, the scattered radiation at the point in question can be obtained. If a point is outside the irradiated area, the contribution from a sector will be the difference between that corresponding to the total radius and that corresponding to the portion of the radius Iying outside the field. The scattered radiation dosage at the points off the beam axis was ealculated with 10-degree intervals. The data were normalized to a dose at the centre of 100 roentgens. The results are shown in Table IV. 
TABLE IV: SCATTERED DOSE: $280 \mathrm{KVP}$

DOSE IN ROENTGENS

\begin{tabular}{lccccc} 
& $\begin{array}{c}\text { Experimental } \\
\text { Results }\end{array}$ & $\begin{array}{c}\text { From Depth } \\
\text { Dose Data }\end{array}$ & \multicolumn{3}{c}{$\begin{array}{c}\text { From Bruce's } \\
\text { Data } \\
\text { Once- }\end{array}$} \\
\hline (Total) & (Total) & Total & $\begin{array}{c}\text { Sultiply- } \\
\text { Scattered }\end{array}$ & Scattered \\
\hline $\begin{array}{l}\text { Centre } \\
1.47 \mathrm{~cm}\end{array}$ & 100 & 100 & 104 & 55 & 49 \\
$\begin{array}{l}\text { Inside } \\
1.88 \mathrm{~cm}\end{array}$ & 73 & 73 & 69 & 42 & 27 \\
Outside & 37 & 21 & - & - & -
\end{tabular}

It can be seen that the agreement is very good for the point inside the field. However, there is a large discrepancy between the values for the outside point. This diserepancy can be explained at least partly by the large and unreliable extrapolation of the depth dose data and back-scatter factors required for this point (8). Bruce (10) has worked out tables for calculating scattered radiation spectra from primary spectral data. Using a primary spectrum measured by Cormack et al (II), the scattered spectrum at the centre was calculated from tables based on Bruce's data. Although Bruce worked out the scattered spectra for points at the central axis only, the scattered spectra at points off the beam axis may be found by the following method. The irradiated area was divided up into sectors as in Clarkson's method (8) and the contributions from each sector were summed up. In this case the contribution from each sector 
takes the form of a spectrum instead of a dose.

The measured spectra were normalized so that the measured and the calculated spectra for the central point would have the same peak height. The comparison is shown in Fig. XI. It can be seen that for the central point the measured spectrum is shifted somewhat to higher energies. For the point inside the field, the magnitude agrees very well, but the shift is much more pronounced. The increase in the discrepancy can be partly attributed to the interpolations and extrapolations from Bruce's calculations. Although the experimental spectra and those calculated from Bruce's tables do not agree very well, the total doses calculated from these spectra are in reasonable agreement as can be seen in Table IV. For the point outside the irradiated area more interpolations and extrapolations would be required. Therefore, it was thought that such a comparison was not worthwhile and was therefore not attempted.

Since Bruce had calculated the once-seattered and the multiplyscattered photons separately, it is interesting to see what portion of the spectrum was due to the once-scattered photons. Graphs showing the separation are shown in Figs. XIIa and XIIb. The dose correspondIng to the once-scattered and to the maltiply-scattered radiation is given in Table IV. The contribution of once-scattered photons to the total dose received consisted of $47 \%$ for the central point compared to $39.5 \%$ for the point $1.47 \mathrm{~cm}$ inside the fleld. Such a difference would be expected since a greater portion of the photons have to travel farther to reach the point near the edge of the beam. Probably the 


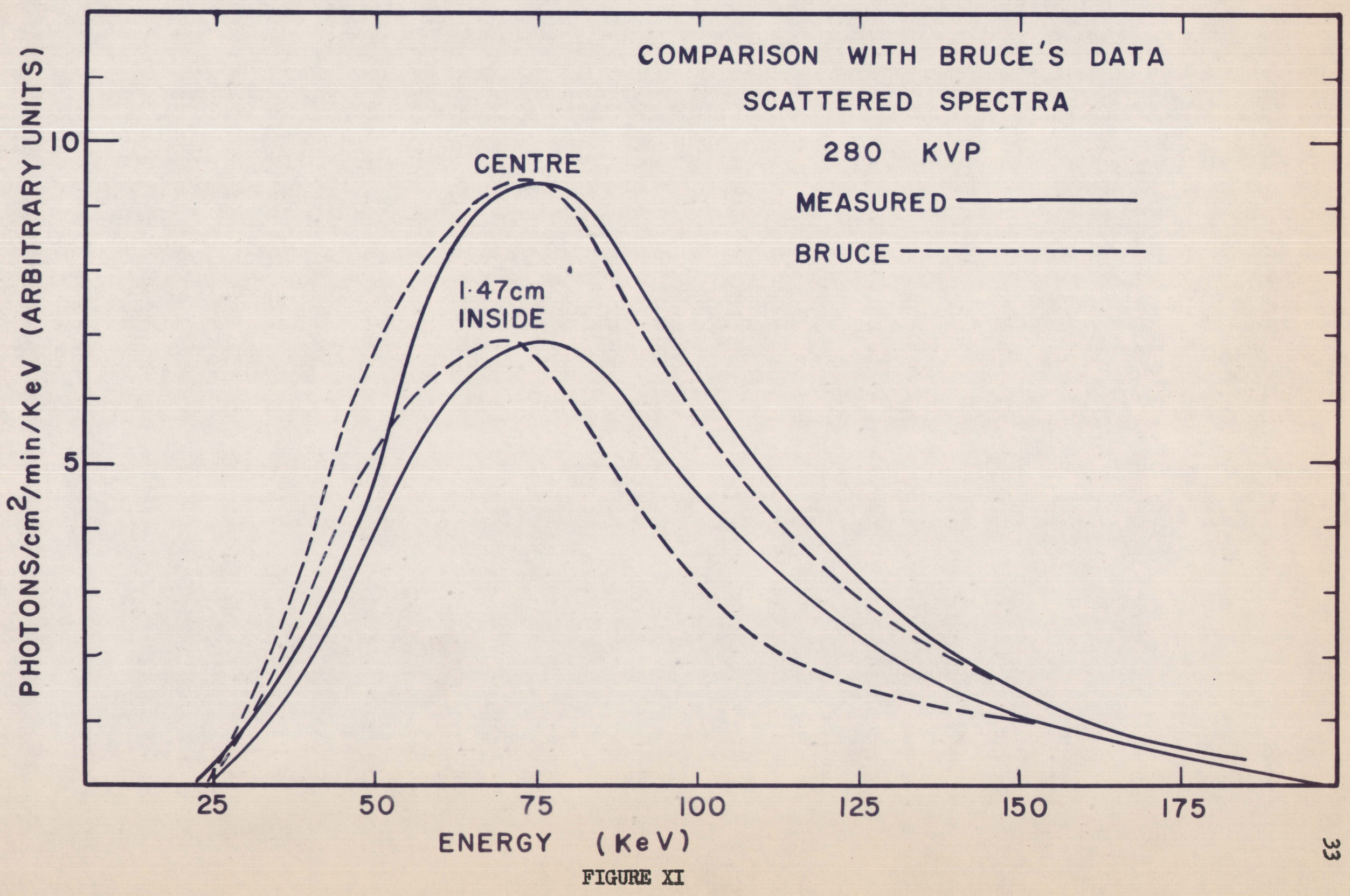




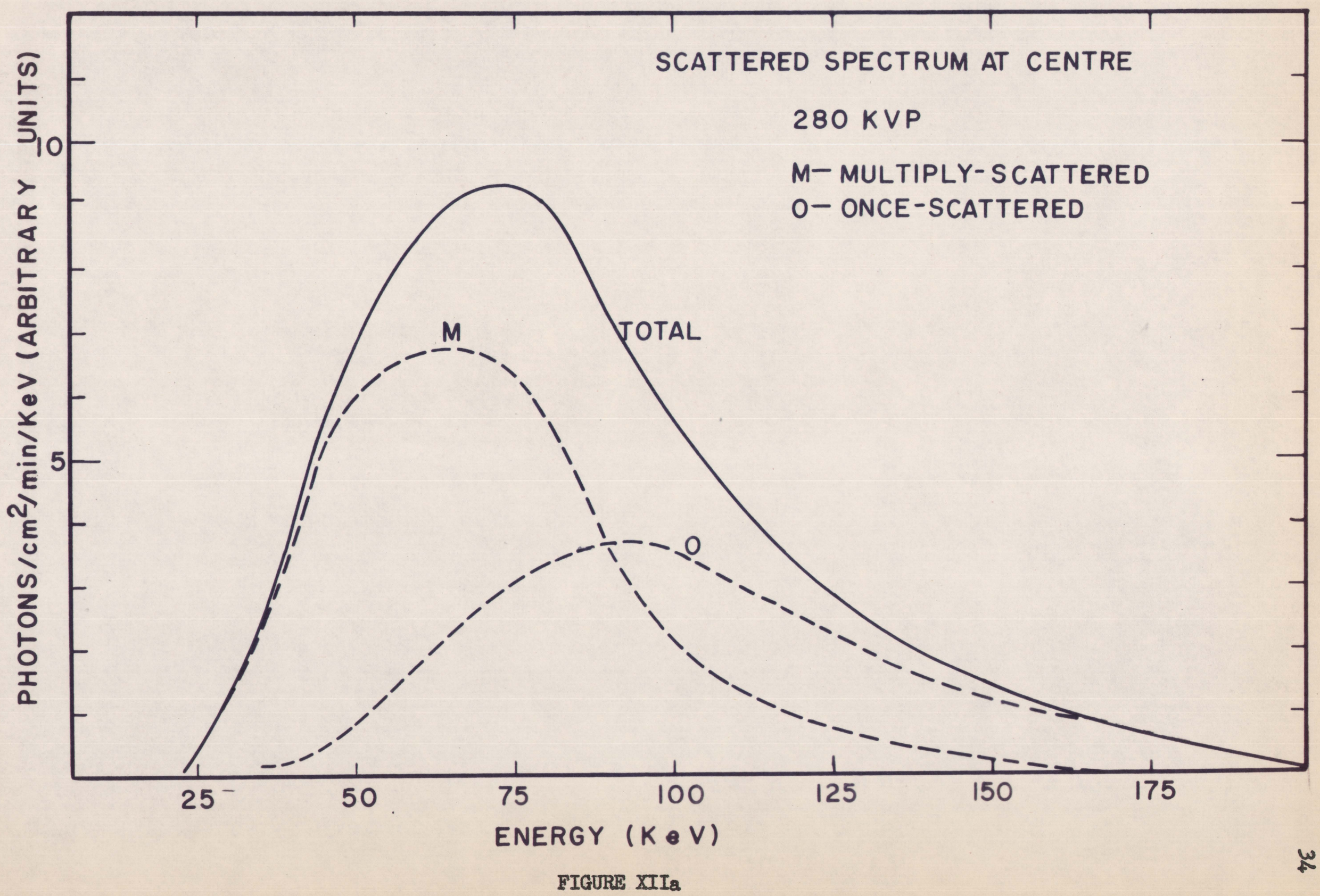




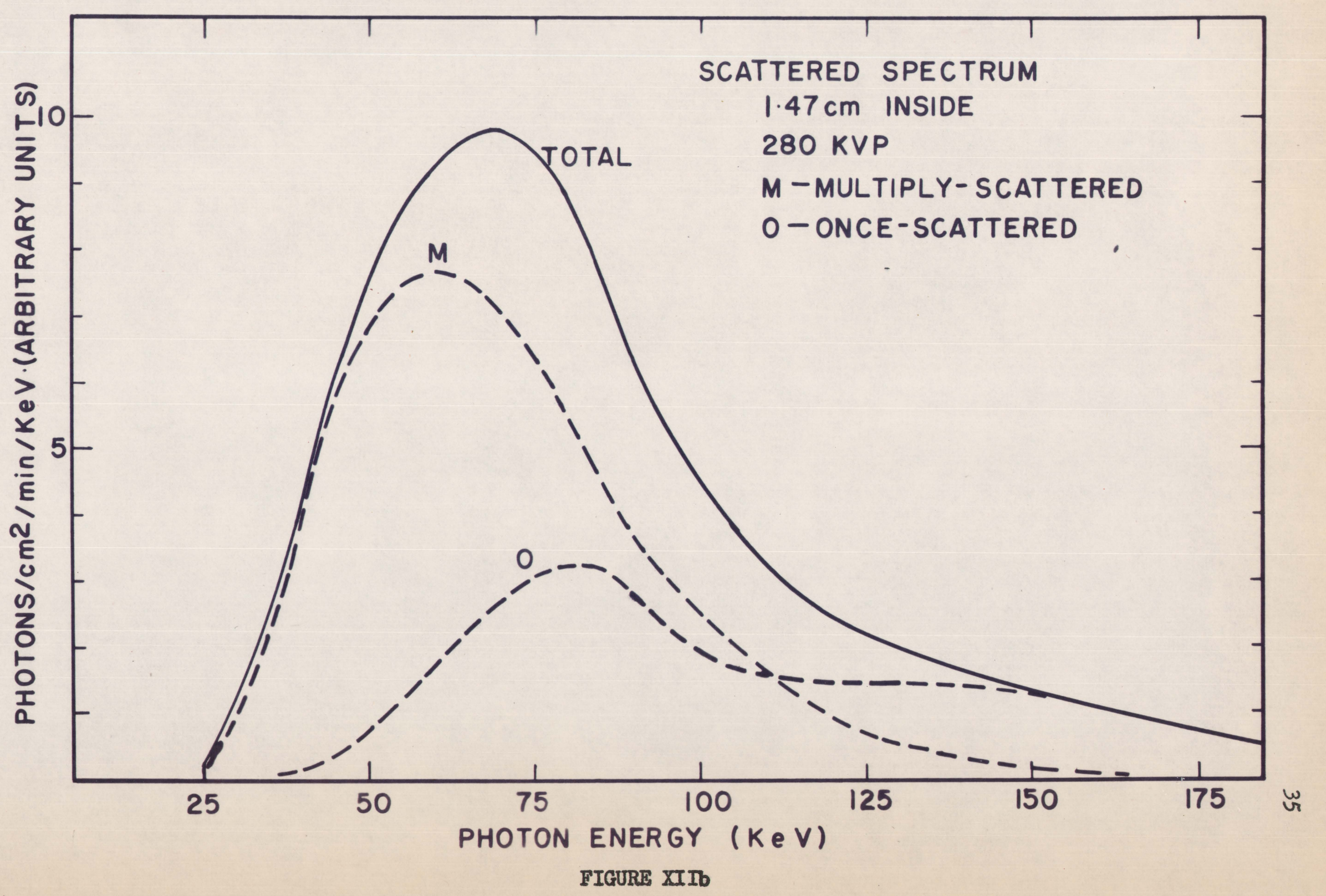


once-scattered photons will contribute a still lower percentage for the point outside the field.

c. $140 \mathrm{KVP}$

As seen in Fig. VIIb there seem to be two peaks in the seattered spectra. They are probably due to the single-scattered photons from the primary peaks which occur at approxdmately 35 and $60 \mathrm{KeV}$ (12). The energles of the scattered peaks agree roughly with those given by the Comption scattering formula. No shift in these peaks was noted as the scattering angle $\theta$ was varied. This would be expected because the energy of the scattered photons varies very little with the scattering angle for these low incident energies, 35 and $60 \mathrm{KeV}$, and the resolution was not good enough to show the change. These scattered peaks also appear in the integrated spectra, but more smeared out.

Unlike the scattered spectra for the $280 \mathrm{KVP}$, the shape of the measured spectrum as well as its magnitude changes with increasing distance from the beam centre (see Fig. $\mathrm{Xb}$ ). As the boundary is crossed the magnitude is greatly reduced. The percentage of reduction was more than that given by the $280 \mathrm{KVP}$ radiation. Martin and Evans (13) have measured the scattered dose outside the irradiated field as a function of distance from the centre of the beam. They showed that as the distance increases the dose falls off more rapidly for the softer radiations than for harder ones. Our calculations confirm their results qualitatively.

A comparison of the dose calculated from our measured spectra 
with that from depth dose data was made for the central point and the inside point only, since the depth dose data are not adequate to make calculations for the outside point. Since Jennings data (14) give maximum focal skin distances of $30 \mathrm{~cm}$ the data had to be extrapolated to a focal skin distance of $60 \mathrm{~cm}$. This was done by the method described by Johns, Bruce and Reid (15). From Bruce's investigations, the ratio between the total dose and the primary dose at that depth is constant without regard to the focal skin distance provided that the depth and area at that depth are the same.

FIGURE XIII

FOCAI SKIN DISTANCE EXTRAPOLATION

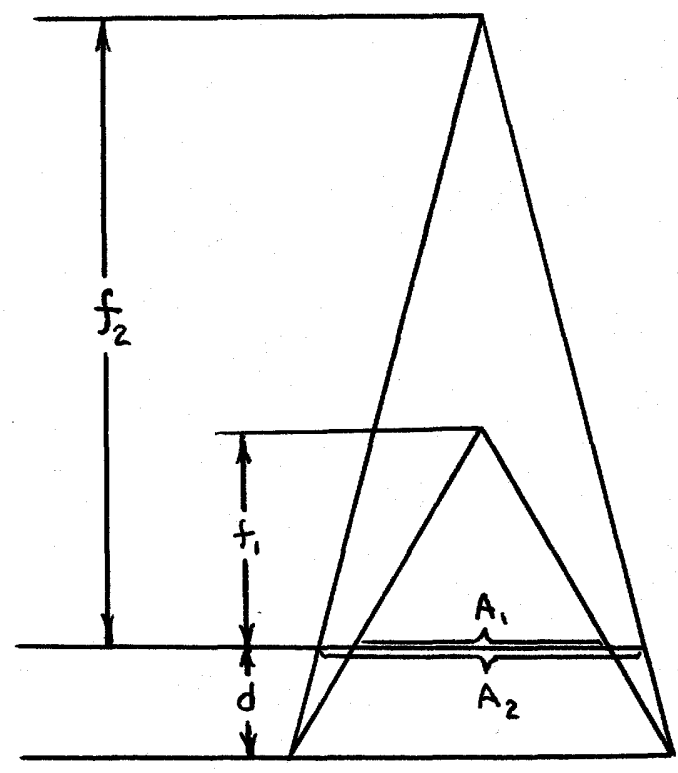

$$
\frac{(\text { Total Dose })_{1}}{(\text { Primary Dose })_{1}}=\text { constant }
$$


To have the same area at depth $d, A_{2}$ corresponding to $f_{2}$ must be reduced by a factor $\left(\frac{f_{1}}{f_{1}+d}\right)^{2}\left(\frac{f_{2}+d}{f_{2}}\right)^{2}$. The primary dose corresponding to $f_{2}$ will also be reduced by the same factor. Then

$$
\frac{(\text { TOTAL DOSE })_{2}}{\left(\frac{f_{1}}{f_{1}+d}\right)^{2}\left(\frac{f_{2}+d}{f_{2}}\right)^{2}(\text { PRIMARY })_{1}}=\text { constant. }
$$

From these considerations, extrapolation to a new focal skin distance $f_{2}$ will be carried out as follows:

The percentage depth dose data for focal skin distance of $f_{1}$ were plotted against area. Values correcponding to an area of $A_{2}\left(\frac{f_{1}}{f_{1}+d}\right)^{2}\left(\frac{f_{2}+d}{f_{2}}\right)^{2}$ were recorded. These values were then divided by $\left(\frac{f_{1}}{f_{1}+d}\right)^{2}\left(\frac{f_{2}+d}{f_{2}}\right)^{2}$ to obtain the percentage depth dose for $f_{2}$.

The remainder of the calculation of the dose at the point near the beam edge was the same as that for $280 \mathrm{KVP}$ radiation. It was again normalized so that the dose at the centre was equal to 100 roentgens. The results are shown in Table $\mathrm{V}$. 
TABLE V: SCATTERED DOSE: $140 \mathrm{KVP}$

DOSE IN ROENTGENS

\begin{tabular}{lcc} 
& $\begin{array}{c}\text { Experimental } \\
\text { Results }\end{array}$ & $\begin{array}{c}\text { Calculated } \\
\text { From Depth } \\
\text { Dose Data }\end{array}$ \\
\hline $\begin{array}{l}\text { Centre } \\
1.47 \mathrm{~cm}\end{array}$ & 100 & 100 \\
$\begin{array}{l}\text { Inside } \\
1.88 \mathrm{~cm}\end{array}$ & 83 & 77 \\
Outside & &
\end{tabular}

It can be seen that the agreement is reasonably good although not so good as the results for $280 \mathrm{KVP} X$-rays. Part of the discrepancy can be attributed to the inaccuracy of the percentage depth dose data. A comparison of data obtained by Jennings and those by Johns et al (16) shows deviations of the order of $10 \%$. Bruce's (10) tables are not applicable to radiations in these energies because the lowest incident energy that Bruce considered was $50 \mathrm{KeV}$ while the primary of $140 \mathrm{KVP}$ radiation had a peak height at about $35 \mathrm{KeV}(12)$. 
SUMMARY

Scattered radiation spectra at both sides of the boundary and at the geometrical centre of an X-ray bean were measured with a scintillation spectrometer. Two types of radiations were used, $280 \mathrm{KVP}$ with HVL of $2.5 \mathrm{~mm} \mathrm{Cu}$ and $140 \mathrm{KVP}$ with BVL of $1.45 \mathrm{~mm} \mathrm{Al}$. The dose received at $1.47 \mathrm{om}$ inside the beam edge was $73 \%$ of that at the centre and $1.88 \mathrm{~cm}$ outside was $37 \%$ of that at the centre for the $280 \mathrm{KVP}$ radiation. For $140 \mathrm{KVP}$ radiation, the dose at $1.47 \mathrm{~cm}$ inside and $1.88 \mathrm{~cm}$ outside was found to be $83 \%$ and $25 \%$ of that at the centre respectively.

Comparisons were made between the measured spectra and those calculated from Bruce's tables for the $280 \mathrm{KVP}$ radiation. The measured spectra agree fairly well both in magnitude and shape with the calculated values. The doses received at these points were compared with those calculated from depth dose data and found to be in fair agreement. 


\section{BIBLIOGRAPHY}

1. Cormack, D.V., Griffith, T.J. and Johns, H.E., Brit. J. Radiol. 30:129, 1957 .

2. Burke, D.G., B. Sc. thesis, J. of S., 1957.

3. Hettinger, G and Starfelt, N., Ark. f. Fys. 14:497, 1959.

4. Cormack, D.V., Burke, D.G. and Davitt, W.E., Radiology 70:91, 1958.

5. Fine, S. and Hendee, C.F., Nucleonics 13; No. 3:36, 1955.

6. Burke, D.G., M. Se. thesis, U. of S., 1958.

7. Rawson, E.G. and Cormack, D.V., Nucleonies 16; No. 10:92, 1958.

8. Clarkson, J.R., Brit. J. Radiol. 14:265, 1941.

9. Johns, H.E. et al, Brit. J. Radiol. Supp. No. 5, pp. 20-37, 1953.

10. Bruce, W.R., Ph. D. thesis, U. of S., 1956.

11. Cormack, D.V., Davitt, W.E., Burke, D.G. and Rawson, E.G., Brit. J. Radiol. 21:565, 1958 .

12. Cormack, D.V. and Burke, D.G., (to be published, Radiology, 1959.)

13. Martin, J.H. and Evans, A., Brit. J. Radiol. 32:7, 1959.

14. Jennings, W.A., Brit. J. Radiol. Supp. No. 5, pp. 7-16, 1953.

15. Johns, H.E., Bruce, W.R. and Reịd, W.B., Brit. J. Radiol. 21:254, 1958.

16. Johns, H.F., Epp, E.R. and Fedoruk, S.0., Brit. J. Radiol. $\underline{26}: 32,1953$. 